\title{
Minireview
}

\section{Management of advanced colorectal cancer: state of the art}

\author{
M Saunders ${ }^{*, I}$ and T Iveson ${ }^{2}$ \\ 'Christie Hospital NHS Trust, Wilmslow Road, Manchester M20 4BX, UK; ${ }^{2}$ Southampton General Hospital, Tremona Road, Southampton SO 16 6YD, \\ UK
}

Colorectal cancer (CRC) caused over 500000 deaths worldwide in 2002. Recent advances in the treatment of advanced disease include the incorporation of two new cytotoxic agents, irinotecan and oxaliplatin, into first-line regimens. The concept of planned sequential therapy involving three active agents during the course of a patient's treatment is evolving. Coupled with the integrated use of targeted monoclonal antibodies, we can now expect overall survival rates for advanced disease to exceed 20 months. This review considers current treatments and suggests where future progress may occur.

British Journal of Cancer (2006) 95, I31 - I38. doi:I0.1038/sj.bjc.6603233 www.bjcancer.com

(c) 2006 Cancer Research UK

Keywords: colorectal cancer; first-line; 5-fluorouracil; irinotecan; oxaliplatin; targeted agents

Globally, over a million cases of colorectal cancer (CRC) were reported in 2002 with the incidence approximately balanced between the sexes. In the same year, over 500000 deaths were attributed to the disease. There is a 25 -fold geographical variation in incidence, presumably as a consequence of dietary factors, with the highest rates of occurrence seen in North America, Australia/ New Zealand, Western Europe and in men especially, Japan (Parkin et al, 2005).

The majority of CRC patients, perhaps $70-80 \%$, present with apparently resectable localised disease. Surgery, followed by adjuvant therapy for high-risk patients, will be the optimum curative treatment approach in such cases. However, ultimately, approximately half of all diagnosed CRC patients will develop disseminated advanced disease, which in most cases will be fatal. Patients with advanced disease who are sufficiently fit usually receive systemic chemotherapy, first-line, but they may receive best supportive care, surgery (or in the case of rectal tumours, radiotherapy) or a combination of these treatments. Their secondline treatment, if any, is dependent on their response to first-line treatment, disease status and performance status. Chemotherapy for advanced disease is an attempt to alleviate and control symptoms, improve quality of life and improve survival. The aim of this review is to outline the efficacy and safety data for the currently available chemotherapy treatment options for patients with advanced CRC.

\section{CHEMOTHERAPY IN THE TREATMENT OF PATIENTS WITH ADVANCED CRC}

For nearly 50 years, 5 -fluorouracil (5-FU) has been the mainstay of chemotherapy treatment for CRC and fluoropyrimidine-based chemotherapy remains a key component of the treatment algorithm for advanced disease, in both the first- and second-

* Correspondence: Dr M Saunders;

E-mail: mark.saunders@christie-tr.nwest.nhs.uk

Received 23 January 2006; revised 29 May 2006; accepted 5 June 2006 line settings. Indeed, until 10 years ago, 5-FU was the only chemotherapy option available to patients. Meta-analyses have shown that chemotherapy for advanced CRC can slow progression and prolong disease survival compared with best supportive care (Colorectal Meta-analysis Collaboration, 2000; Simmonds, 2000). 5 -FU in combination with the biomodulator folinic acid (FA) increases the response rate (RR) compared with 5-FU alone (21 vs $11 \%)$ and confers a small but significant (11.7 vs 10.5 months) survival advantage (Thirion et al, 2004). Likewise, 5-FU administered as a continuous infusion has superior efficacy when compared with 5-FU administered as an intravenous (i.v.) bolus (RR 22 vs 14\%) (Meta-analysis Group in Cancer, 1998a). Furthermore, infusional 5-FU regimens have also been shown to be associated with fewer World Health Organization grades 3 and 4 toxicities (Meta-analysis Group in Cancer, 1998b). Generally, physicians in Europe have preferred infusional delivery; with bolus regimens preferred by physicians in the US. However, increasingly there is a shift towards the use of infusional regimens in the US as it is recognised that they are associated not only with a more manageable toxicity profile but also with increased efficacy. The dosing schedules for commonly used bolus and infusional 5-FU-based regimens are summarised in Table 1.

The future of 5-FU-based therapy for the treatment of advanced CRC lies in its combination with newer agents with nonoverlapping toxicity profiles, such as the topoisomerase I inhibitor irinotecan (CPT11, Campto ${ }^{\circledR}$ ) and the third-generation platinum compound oxaliplatin (Eloxatin ${ }^{\mathbb{R}}$ ). Indeed, the infusional 5-FU component of current regimens may be replaced in the future by the new oral fluoropyrimidines, capecitabine (Xeloda ${ }^{\mathrm{R}}$ ) and uracil-tegafur $\left(\mathrm{UFT}^{\mathbb{R}}\right)$, prodrugs that are designed to mimic infusional 5-FU treatment (Rich et al, 2004).

Two key studies demonstrated the superior activity of irinotecan/5-FU/FA compared to 5-FU/FA alone (Douillard et al, 2000; Saltz et al, 2000), leading to the approval of irinotecan for the first-line treatment of advanced CRC in both the US and Europe in 2000. Likewise, oxaliplatin in combination with infusional 5-FU/FA was approved for use in the first-line setting in Europe in October 1999 and in the US in combination with 5-FU/FA in January 2004. 
Table I Summary of frequently used bolus and infusional 5-FU/FA regimens

Regimens

Mayo Clinic Regimen (Saltz et al, 2000)

Saltz (modified Roswell Park regimen)

(Saltz et al, 2000)

De Gramont (de Gramont et al, 1997)

Modified de Gramont (Leonard et al, 2002)

AlO (Köhne et al, 2005)
Doses and schedules of administration

5-FU (425 $\mathrm{mg} \mathrm{m}^{-2}$ day $\left.^{-1}\right)$ i.v. bolus+FA $\left(20 \mathrm{mg} \mathrm{m}^{-2}\right.$ day $\left.^{-1}\right)$ daily days I - 5 every 4 weeks

5-FU $\left(500 \mathrm{mg} \mathrm{m}^{-2} \mathrm{day}^{-1}\right)$ i.v. bolus+FA $\left(20 \mathrm{mg} \mathrm{m}^{-2}\right.$ day $\left.^{-1}\right)$ weekly for 4 weeks every 6 weeks

FA $\left(200 \mathrm{mg} \mathrm{m}^{-2}\right) 2 \mathrm{~h}+5$-FU $\left(400 \mathrm{mg} \mathrm{m}^{-2}\right)$ i.v. bolus $+22 \mathrm{~h}$ infusion 5-FU $\left(600 \mathrm{mg} \mathrm{m}^{-2}\right)$ for 2 consecutive days every 2 weeks FA $\left(175-200 \mathrm{mg} \mathrm{m}^{-2}\right) 2 \mathrm{~h}+5$-FU $\left(400 \mathrm{mg} \mathrm{m}^{-2}\right)$ i.v. bolus $+46 \mathrm{~h}$ infusion 5 -FU $\left(2400-3000 \mathrm{mg} \mathrm{m}^{-2}\right)$ for 2 consecutive days every 2 weeks

5-FU $\left(2600 \mathrm{mg} \mathrm{m}^{-2}\right) 24 \mathrm{~h} \mathrm{Cl+FA}\left(500 \mathrm{mg} \mathrm{m}^{-2}\right)$, weekly $\times 6$, every 7 or 8 weeks

$\mathrm{AIO}=$ Arbeitsgemeinschaft Internische Onkologie (German Co-operative Group); $\mathrm{Cl}=$ continuous infusion; FA = folinic acid; 5-FU =5-fluorouracil; i.v. = intravenous.

\section{IRINOTECAN IN THE FIRST-LINE TREATMENT OF ADVANCED CRC}

Three published phase III trials evaluated the role of irinotecan in combination with 5-FU/FA vs 5-FU/FA alone in the first-line setting. Two European trials investigated infusional 5-FU/FA regimens (de Gramont and Arbeitsgemeinschaft Internische Onkologie (AIO)); (Douillard et al, 2000; Köhne et al, 2005), whereas a US trial investigated a bolus 5-FU/FA regimen (Saltz et al, 2000). Irinotecan in combination with the bolus 5-FU/FA regimen was subsequently shown to be associated with high 60 -day mortality levels (Sargent et al, 2001) and is now generally the less favoured way of administering this combination.

The addition of irinotecan to 5-FU/FA, irrespective of regimen, conferred a significant clinical benefit, in terms of RR (35 vs 22, 39 vs 21, 54 vs 32\%), progression-free survival (PFS: $6.7 v s$ 4.4, $7.0 v s$ $4.3,8.5$ vs 6.4 months) and overall survival (17.4 vs 14.1, 14.8 vs 12.6, 20.1 vs 16.9 months) compared with the corresponding 5-FU/ FA regimen alone (respectively for Douillard et al, 2000; Saltz et al, 2000; Köhne et al, 2005). Also, although the more recent phase III study of Köhne et al, failed to demonstrate a statistically significant improvement in overall survival, the trend of $>3$ months increase led to one of the longest median overall survival times, to date, in this clinical setting. One can envisage that except for the crossover to irinotecan-based therapy, second-line, in the control 5-FU/FA arms of all three trials, these differences might have been even greater.

The addition of irinotecan to 5-FU/FA did not result in unacceptable toxicity, although it was associated with a higher incidence of grade 3 diarrhoea compared with bolus or infusional 5-FU/FA alone. Importantly, some key 5-FU-associated toxicities: neutropenia, neutropenic fever or sepsis and mucositis were reduced owing to the lower 5-FU dose administered in the combination regimens. The time to deterioration in performance status was also significantly longer for those patients receiving irinotecan/5-FU/FA (Saltz et al, 2000).

\section{OXALIPLATIN IN THE FIRST-LINE TREATMENT OF ADVANCED CRC}

Published phase III trials similarly reported that in combination with infusional (de Gramont et al, 2000) or chronomodulated (Giacchetti et al, 2000) 5-FU/FA, a second new agent, oxaliplatin, was also effective first-line in the treatment of advanced CRC. RRs ( 51 vs 22 and 53 vs 16\%, respectively) and median PFS times (9.0 vs 6.2 and 8.7 vs 6.1 months) were improved in the oxaliplatin/5-FU/ FA arms compared to the 5-FU/FA alone arms. The improvements in these end points were not, however, accompanied by corresponding significant increases in median overall survival in the oxaliplatin arms, which may be attributable to the use of active salvage therapies for both treatment arms in each study.

Although mild gastrointestinal and haematological side effects are commonly associated with oxaliplatin therapy, the principle dose-limiting toxicities are neurotoxicity (which may be acute or chronic) and neutropenia (Grothey and Goldberg, 2004). Acute neurotoxicity (paresthesias or dysesthesias), although frequently seen, is generally transient and mild (Gamelin et al, 2002). However, after several cycles of oxaliplatin therapy, a late-onset cumulative sensory neuropathy may occur. This side effect typically improves rapidly with the discontinuation of oxaliplatin treatment (Grothey, 2003).

\section{RELATIVE EFFICACY OF FIRST-LINE COMBINATIONS}

Comparison of oxaliplatin combined with an infusional 5-FU/FA regimen (FOLFOX) with irinotecan in combination with bolus 5-FU/FA (IFL) in the US intergroup study (Goldberg et al, 2004) suggested that the FOLFOX combination was superior in terms of first-line efficacy. These results formed the basis of the Food and Drug Administration approval of FOLFOX as a first-line therapy for advanced CRC in January 2004. However, the bolus 5-FU component of the IFL regimen is known to be inferior in terms of efficacy to the infusional 5-FU component of FOLFOX (Metaanalysis Group in Cancer, 1998a) and so conclusions cannot be safely drawn from this study concerning relative efficacy of FOLFOX and irinotecan in combination with infusional 5-FU/FA (FOLFIRI).

However, the relative efficacy of these two regimens was directly compared in the randomised Tournigand trial (Tournigand et al, 2004). Although this study was primarily designed to investigate whether the sequence of administration of FOLFOX and FOLFIRI was important in terms of second PFS (the time from randomisation until disease progression after second-line therapy), it provides an important insight into the relative efficacies of these combinations in both the first- and second-line settings. Patients were randomised to one of the two treatment arms. Those in arm A received FOLFIRI (irinotecan $180 \mathrm{mg} \mathrm{m}^{-2}$ and FA $200 \mathrm{mg} \mathrm{m}^{-2}$ on day 1 , followed by bolus 5 -FU $400 \mathrm{mg} \mathrm{m}^{-2}$ and continuous 5 -FU, $2400-3000 \mathrm{mg} \mathrm{m}^{-2}$, by $46-\mathrm{h}$ infusion) until disease progression or unacceptable toxicity, at which time they crossed over to receive oxaliplatin (100 $\mathrm{mg} \mathrm{m}^{-2}$ on day 1$)$ in combination with the same modified de Gramont (MdG) 5-FU/FA regimen (FOLFOX6). Conversely, the patients assigned to arm B received FOLFOX6 until disease progression, at which time they crossed over to receive FOLFIRI.

The median overall survival was 21.5 months for the 109 patients in arm A (FOLFIRI followed by FOLFOX6) and 20.6 months for the 111 patients assigned to arm B (FOLFOX6 followed by FOLFIRI), leading to the conclusion that the two regimens were essentially indistinguishable in terms of efficacy. However, it was noted that a significantly higher number of patients in arm $B$ had their metastatic disease rendered resectable $(P=0.02)$. As expected, the toxicity profiles in first-line therapy of the two regimens were different, with grade $3 / 4$ mucositis and nausea/ 
vomiting more common with FOLFIRI and grade 3/4 neutropenia and neurosensory toxicity more frequent with FOLFOX6. In particular, the number of patients who had to stop oxaliplatin therapy before tumour resistance owing to neurotoxicity was a limitation of the study. The most important observation from the Tournigand study was therefore that median survival was in excess of 20 months for both arms when the two combinations were used sequentially (effectively, the use of three active drugs during the course of the patient's treatment).

The UK MRC CR08 FOCUS trial was designed to assess the role of irinotecan or oxaliplatin combined with the modified MdG infusional 5-FU/FA regimen, in the first- and second-line treatment of patients with advanced CRC. Patients (2135) with good performance status were randomly allocated to one of five treatment arms (Figure 1): staged single-agent therapy (arm A), staged combination therapy (arms B and D) or first-line combination therapy (arms C and E). Only slight (nonsignificant) increases in overall survival were seen with each combination therapy (hazard ratios: $0.86-0.96$ ) over the staged single-agent arm (Seymour, 2005). This suggests that staged combination therapy may provide an alternative treatment strategy for those patients unable to tolerate first-line combinations.

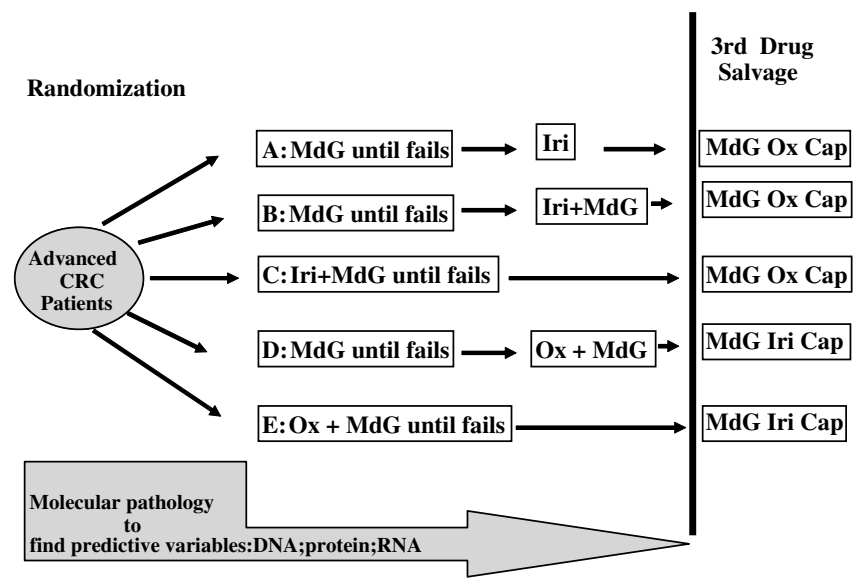

$\mathrm{CRC}=$ colorectal cancer; $\mathrm{MdG}=$ Modified de Gramont (infusional 5-FU/FA); Iri = Irinotecan; Ox = Oxaliplatin; Cap = Capecitabine

Figure I Randomisation for the MRC CR08 FOCUS trial.
Interestingly, rather than use of irinotecan- and oxaliplatinbased regimens sequentially, impressive efficacy data have been reported from a randomised phase III study in which biweekly irinotecan, oxaliplatin and infusional 5-FU/FA (FOLFOXIRI) was compared first-line to FOLFIRI in 244 previously untreated advanced CRC patients (Falcone et al, 2006). FOLFOXIRI was assessed as feasible with manageable toxicities. After a median follow-up of 14 months, RRs were significantly higher (66 vs 41\%, $P=0.0002)$ and PFS was significantly longer (9.8 vs 6.8 months, $P=0.0002)$ in the FOLFOXIRI arm. Full efficacy data are awaited with interest.

In summary, considering all of the published data and acknowledging that the side-effect profiles for each drug are different, it would appear that at least for the moment, a clear case cannot be made for the preferential use of either irinotecan or oxaliplatin in first-line combinations (Punt, 2005). However, other factors such as the relative efficacy of these drugs in the adjuvant setting might in the future direct which agent is used first-line.

\section{THE INFLUENCE OF SECOND-LINE THERAPY ON SURVIVAL}

The importance of effective second-line therapy was first highlighted by the early phase III trials in which single-agent irinotecan was used as salvage therapy (Cunningham et al, 1998; Rougier et al, 1998). The FOLFIRI/FOLFOX crossover in the Tournigand study achieved the longest survival recorded to date, for a phase III trial in advanced CRC. An interesting question is how much did crossover therapy contribute to the clinically significant benefits in survival of over 2-3 months reported for the phase III trials of irinotecan/5-FU/FA in the first-line setting (Douillard et al, 2000; Saltz et al, 2000; Köhne et al, 2005)?

It should be noted that only $50-60 \%$ of patients may actually be well enough to receive such second-line therapy, and consequently, for a significant number of patients, the choice of an optimum first-line regimen is critical. However, if we compare the survival data for trials of irinotecan/5-FU/FA and oxaliplatin 5-FU/FA combinations (Table 2), we can see that overall survival appears to increase in proportion to the number of patients who are able to receive second-line therapy.

Significantly, Grothey and Sargent (2005), in a recent analysis of 21 arms of 11 phase III trials, have shown overall survival to be significantly correlated with the percentage of patients who received all three active drugs (irinotecan, oxaliplatin, 5-FU/FA) during the course of their disease $(P=0.0001)$, and not simply with

Table 2 Survival data for patients who received irinotecan/5-FU/FA or oxaliplatin/5-FU/FA combination therapy first-line: influence of second-line therapy on survival

\begin{tabular}{lcccc}
\hline First-line regimen & $\begin{array}{l}\text { Patients receiving } \\
\text { therapy second-line (\%) }\end{array}$ & $\begin{array}{l}\text { Patients receiving } \\
\text { three active drugs } \mathbf{s}^{\mathbf{a}} \text { (\%) }\end{array}$ & Median OS (months) & Study data \\
\hline Irinotecan+bolus 5-FU/FA & 52 & 5 & 14.8 & Saltz et al (2000) \\
Irinotecan+bolus 5-FU/FA & 67 & 24 & 15.0 & Goldberg et al (2004) \\
Irinotecan+inf. 5-FU/FA & 39.4 & 15.7 & 17.4 & Douillard et al (2000) \\
Irinotecan+AIO & 56 & 52 & 20.1 & Köhne et al (2005) \\
Irinotecan+inf. 5-FU/FA & 81 & 74 & 21.5 & Tournigand et al (2004) \\
FOLFOX & 58 & 29.5 & 16.2 & De Gramont et al \\
FOLFOX & 75 & 60 & 19.5 & Goldberg et al (2004) \\
FucOX & $\mathrm{NA}$ & $\mathrm{NA}$ & 19.4 & Giacchetti et al (2000) \\
FOLFOX & 74 & 62 & 20.6 & Tournigand et al (2004) \\
FUFOX (bolus 5-FU/FA & 81 & 67.5 & 20.4 & Grothey et al (2004) \\
(Mayo Clinic)) & & & &
\end{tabular}

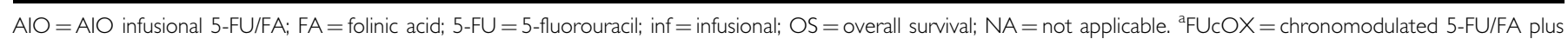
oxaliplatin. ${ }^{a}$ (5-FU/FA, irinotecan and oxaliplatin) during first- and second-line treatment. 
the percentage of patients who received any second-line chemotherapy (Grothey et al, 2004). Although the first-line use of a chemotherapy doublet over 5-FU/FA alone was not associated with a significant efficacy benefit in the expanded analysis (Grothey and Sargent, 2005), the early use of combination therapy increases the likelihood that a patient will receive all three active drugs during their treatment.

\section{HEPATIC RESECTION}

Approximately half of CRC patients develop liver metastases during the course of their disease. Potentially curative surgical resection of secondary tumours is an option for less than $20 \%$ of such patients. In the remainder, the hepatic lesion is either ill sited, too large or multinodular, and therefore deemed to be unresectable. In a proof-of-principle retrospective study, evaluating a chronomodulated schedule of 5-FU/FA and oxaliplatin, Giacchetti et al (1999) demonstrated that first-line cytotoxic chemotherapy had downsized a significant fraction of unresectable disease to operability. Specifically, following the treatment of 151 patients with liver-only, previously inoperable metastatic disease, 77 were subsequently resected with curative intent. Median overall survival in this group was 48 months against 15.5 months in the nonoperated patients.

A recent analysis of all published trials and retrospective studies that had reported tumour response and resection rates of initially unresectable hepatic lesions highlighted how effective this approach can be in advanced CRC. For patients with inoperable metastases confined to the liver (selected patients), resection rates after first-line chemotherapy with a range of regimens were 24$54 \%$, and for all patients with advanced disease (unselected patients), the rate was $1-26 \%$. A highly significant correlation between tumour response and resection rates was seen for both selected and unselected patients, indicating that regimens that produce the highest RRs are likely to be those that allow the highest hepatic resection rates (Folprecht et al, 2006). One factor that should be considered in such evaluations is that a partial response to treatment is often sufficient and preferable for the facilitation of potentially curative liver resection.

The recent phase II study of Alberts et al (2005) confirmed the efficacy of FOLFOX4 in the neoadjuvant setting, with 25 of the 42 $(60 \%)$ assessable patients with nonoptimally resectable liver-only metastatic disease showing a reduction of tumour burden and $17(40 \%)$ patients subsequently undergoing surgery following a median of 6 months of chemotherapy. A high recurrence rate of $71 \%$ after a median follow-up of 22 months was observed in this study for patients who underwent complete resection. It is to be hoped that the addition of targeted agents to FOLFOX might further improve efficacy in this setting. Consideration is also being given to the question of whether perioperative FOLFOX4 is feasible and clinically effective in the randomised phase III EORTC 40983 study. Early results suggest that such treatment can be administered safely and without interfering with the timing of surgery (Nordlinger et al, 2005). Efficacy data are awaited with interest.

\section{CHOICE OF FIRST-LINE TREATMENT FOLLOWING ADJUVANT THERAPY}

There is, however, a change in the dynamics of the treatment for CRC emerging. Oxaliplatin/5-FU/FA has been shown to prolong disease-free survival in patients undergoing curative resection for stage II and III CRC compared with 5-FU/FA alone (Andre et al, 2004), and has consequently been approved for the adjuvant therapy of patients with stage III CRC. It is likely that this will in turn lead to the increased use of irinotecan/5-FU/FA first-line for advanced disease. This possibility is further strengthened by the disappointing data from adjuvant therapy trials of irinotecan/5-
FU/FA combinations. In particular, after a median follow-up of 32 months, the PETACC3 study has so far failed to show a statistically significant survival benefit from adding irinotecan to an infusional 5-FU/FA regimen in stage III colon cancer patients (Van Cutsem et al, 2005). As oxaliplatin-based combination adjuvant therapy may be more appropriate for patients with curatively resected colon cancer, the likelihood of irinotecan being used in the firstline setting upon relapse is increased. However, if the disease-free interval is prolonged after oxaliplatin-based adjuvant therapy, then rechallenging a patient with oxaliplatin when they re-present with metastatic disease could be considered. However, if a patient is troubled by persistent neuropathy after adjuvant oxaliplatin, then it would not be appropriate to reintroduce this agent and therefore irinotecan-based therapy may be preferred.

\section{ORAL FLUOROPYRIMIDINE THERAPY}

It is possible that in the future, the orally active prodrug, capecitabine, will increasingly replace 5-FU in combined regimens. Capecitabine is preferentially activated in neoplastic tissue by a process that exploits the high thymidine phosphorylase enzyme activity in tumours, thereby providing continuous targeted fluoropyrimidine exposure without the inconvenience for the patient of infusional delivery (Rich et al, 2004). Phase III trials in advanced CRC have shown an improved safety profile over bolus 5-FU/FA (Mayo Clinic regimen) (Van Cutsem et al, 2004a) and a recent randomised crossover trial has confirmed a high level of patient preference for oral over i.v. fluoropyrimidine therapy (Twelves et al, 2006). Capecitabine was also shown in the adjuvant setting to be at least equivalent in terms of efficacy to bolus 5-FU/ $\mathrm{FA}$, with a significant increase in relapse-free survival in the capecitabine $v s$ 5-FU/FA group $(P=0.04)$ (Twelves et al, 2005). However, one recent report of a randomised phase III trial of firstline infusional 5-FU/FA/oxaliplatin (FUFOX) $v s$ capecitabine plus oxaliplatin (CAPOX) has so far failed to exclude the inferiority of the CAPOX regimen (Kubicka et al, 2006). Indeed, it has been argued that combinations of capecitabine with oxaliplatin or irinotecan are currently probably best placed within clinical trial settings (Köhne and Folprecht, 2006).

\section{TARGETED AGENTS}

As our knowledge of tumour biology and genetics matures, a range of agents that interact with novel disease-associated targets are emerging into the clinical setting. Two drugs already approved for the treatment of CRC are the monoclonal antibodies: cetuximab $\left(\right.$ Erbitux ${ }^{\mathbb{R}}$ ), which binds to and inhibits activation of the epidermal growth factor receptor (EGFR) (Li et al, 2005), and bevacizumab (Avastin ${ }^{\mathbb{R}}$ ), which binds vascular endothelial growth factor (VEGF-A), thereby interfering with signalling through the VEGF1 and -2 receptors and inhibiting angiogenesis (Hicklin and Ellis, 2005). Most of the mature data relating to the efficacy of targeted agents in CRC treatment have been derived using irinotecan combinations. However, considerable evidence is now emerging that, as expected, these targeted drugs are not agent specific and that they are likely to improve the efficacy of both irinotecan and oxaliplatin combinations.

\section{Cetuximab}

Cetuximab has been approved in both Europe and the US for use in combination with irinotecan as second-line therapy in CRC patients who have failed prior irinotecan treatment. In the pivotal study, Cunningham et al (2004) randomised 329 previously treated patients who had progressed during or immediately following irinotecan-based therapy into two groups, which received either cetuximab plus irinotecan (218) or cetuximab (111). They 
demonstrated a higher RR (22.9 vs $10.8 \%)$ and an increase in the median time to progression (4.1 vs 1.5 months) for the combination therapy group compared to the monotherapy group.

Cetuximab was subsequently investigated first-line in combination with irinotecan/infusional 5-FU/FA (Rougier et al, 2004; Folprecht et al, 2006). Initial results showed these combinations to be safe with promising activity. Early data also suggested that cetuximab combined with FOLFOX is an active and safe combination in the first-line treatment of CRC (Polikoff et al, $2005)$. Indeed, the confirmed RR of $72 \%$ to cetuximab/FOLFOX 4 in one first-line phase II trial is one of the highest so far recorded for this setting and resulted in a resection rate for initially inoperable metastatic disease of $23 \%$ in the unselected patient series (DiazRubio et al, 2005).

Cetuximab does not appear to increase the intensity or frequency of the characteristic side effects of cytotoxic chemotherapy. The most common cetuximab-related adverse event reported is the development of an acne-like rash. This class effect of EGFR inhibitors is generally manageable (Segaert et al, 2005) and may be indicative of a response to cetuximab (Van Cutsem et al, 2004b).

\section{Bevacizumab}

Bevacizumab in combination with irinotecan/bolus 5-FU/FA has been approved for the first-line therapy of patients with advanced CRC based on the data from the Hurwitz trial (Hurwitz et al, 2004). Patients in this study (813) were randomised into two groups:
irinotecan/5-FU/FA/bevacizumab (402) vs irinotecan/5-FU/FA plus placebo (411). There was an improved median duration of survival (20.3 vs 15.6 months), an increased RR (44.8 vs 34.8\%) and a longer median progression-free survival (10.6 vs 6.2 months) in the bevacizumab over the placebo arm.

The second-line use of bevacizumab in combination with oxaliplatin was subsequently explored in the randomised phase III ECOG 3200 study, which investigated the efficacy and safety of bevacizumab alone and in combination with FOLFOX4 vs FOLFOX4 alone in 829 CRC patients previously treated with irinotecan and a fluoropyrimidine (Giantonio et al, 2005). After a median follow-up period of 18.7 months, there was a statistically significant advantage in the bevacizumab/FOLFOX4 arm $v s$ the FOLFOX arm for both overall survival and PFS (12.5 vs 10.7 and 7.4 vs 5.5 months).

The first-line use of bevacizumab has also been investigated in the sequential randomised TREE- 1 and TREE- 2 trials. The TREE- 1 study was initially designed to evaluate the efficacy and safety of three different oxaliplatin and fluoropyrimidine combinations: FOLFOX, oxaliplatin/bolus 5-FU/FA (bFOL) and capecitabine and oxaliplatin (CapOx). Following the regulatory approval of bevacizumab in 2004, TREE-2 was initiated with the aim of evaluating the benefits of bevacizumab in combination with the same regimens. Cross-study comparison suggested that the addition of bevacizumab improved the RR and median time to progression in each arm of the study (Hochster et al, 2005, 2006). Overall survival data are eagerly awaited.

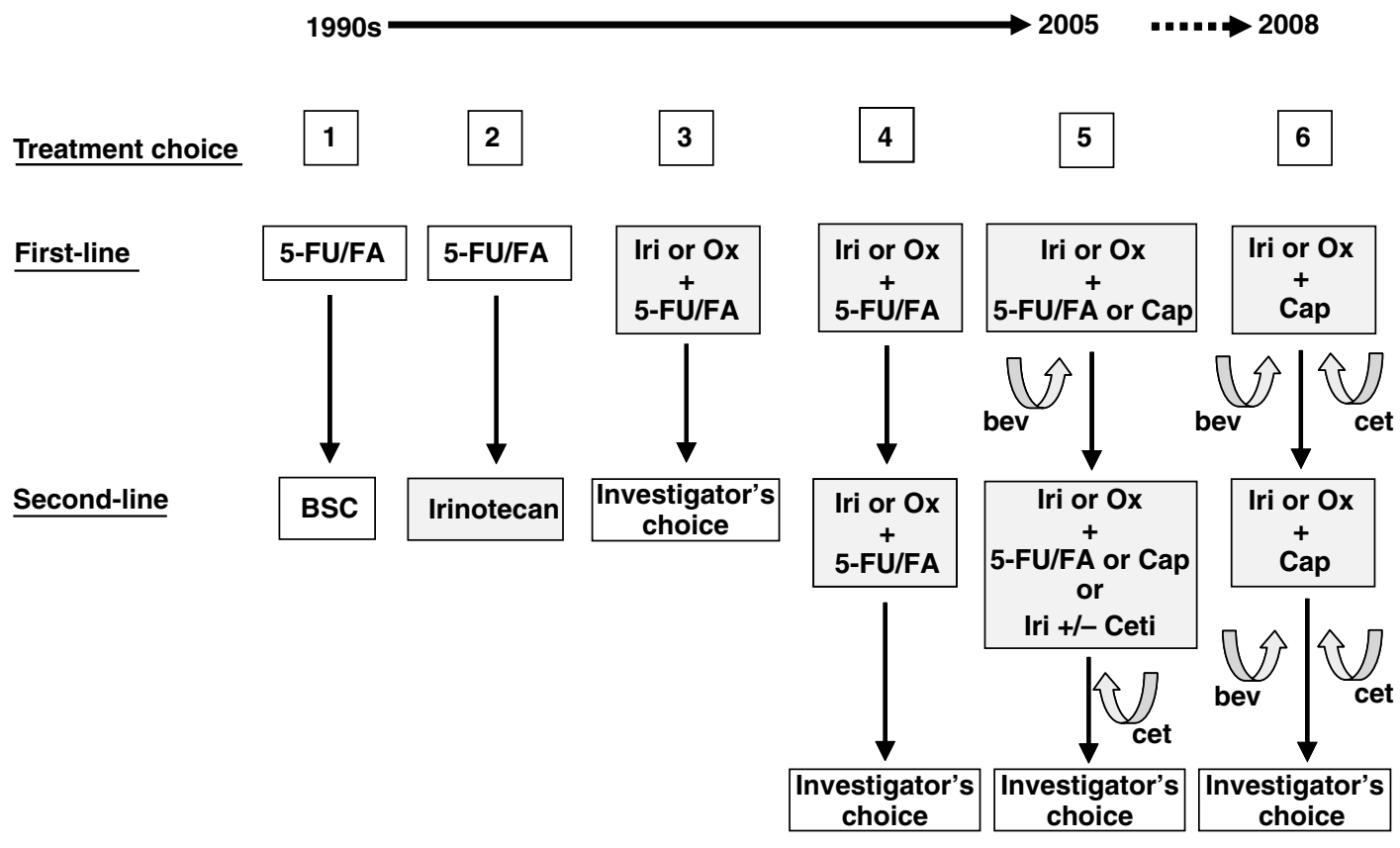

Number of therapies

2

2

3

3

3

Survival

10-12 months

21.5 months $\cdots \rightarrow$ ?

\begin{tabular}{|c|c|c|c|c|}
\hline $\begin{array}{c}\text { Maughan, } \\
2002\end{array}$ & $\begin{array}{c}\text { Rougier, 1998 } \\
\text { NICE, 2002 }\end{array}$ & $\begin{array}{c}\text { Douillard, 20000 } \\
\text { De Gramont, 2000 }\end{array}$ & $\begin{array}{c}\text { Tournigand, } \\
2004\end{array}$ & $\begin{array}{c}\text { Hurwitz, 2004 } \\
\text { Cunningham, 2004 }\end{array}$ \\
\hline
\end{tabular}

Figure 2 Expansion of the treatment choices for patients with advanced CRC (Rougier et al, 1998; de Gramont et al, 2000; Douillard et al, 2000; Maughan et al, 2002; Cunningham et al, 2004; Hurwitz et al, 2004; Tournigand et al, 2004) Iri= irinotecan; Ox= oxaliplatin; Cap=capecitabine; bev = bevacizumab; cet = cetuximab; $\mathrm{BSC}=$ best supportive care. 
The use of bevacizumab has been associated with a low level of gastrointestinal perforation events (Kozloff et al, 2006) and some concern has been expressed as to whether anti-VEGF therapy might inhibit wound healing (Scappaticci et al, 2005). This concern led to the recommendation that a patient should not undergo elective hepatic resection during or within 8 weeks of bevacizumab treatment (Ellis et al, 2005).

\section{FUTURE DIRECTIONS: 'PERSONALISED' THERAPY}

New targeted agents directed against specific proteins and pathways are likely to continue to improve our ability to treated advanced CRC. In addition, considerable evidence indicating that the expression levels or functionality (coding sequence variation) of certain genes can affect either how a tumour or a patient responds to a particular drug is also accumulating. Typing such variation before treatment begins may allow the physician in the future to select on a case-by-case basis the most appropriate treatment agents or dose levels (reviewed by Russo et al, 2005). An example of the potential of this approach is provided by recent data suggesting that constitutional allelic variation in UDPglucuronosyltransferase, a protein involved in the metabolism of irinotecan, may predict response and toxicity in patients with advanced CRC treated with capecitabine/irinotecan (Carlini et al, 2005). Prospective studies are clearly required to validate such observations and to extend their scope to include wider considerations of other ADME (absorption, distribution, metabolism, excretion) genes, for example, the ATP-binding cassette transporters, which can contribute to irinotecan efflux (Rhodes et al, 2005).

The use of such approaches is clearly some way in the future. However, the strong possibility that the performance of existing effective treatments might be further improved by the considera- tion of the genetic background of the patient and/or the genetic/ epigenetic status of the tumour is an enticing prospect. If we are to realise this potential, the collection and analysis of appropriate biological material from trial participants needs to be routinely carried out in current and future studies. Subsequent analyses will be facilitated by the progressively decreasing costs of genomics and genotyping technologies.

\section{CONCLUSIONS}

The use of irinotecan or oxaliplatin in combination with 5-FU/FA first-line is consistently associated with a clinically significant improvement in survival. If oxaliplatin is used more widely in the adjuvant setting, as seems likely given the data from recent trials, the use of irinotecan as first-line therapy is likely to increase in the future. The use of three cytotoxic drugs (irinotecan, oxaliplatin and 5-FU/FA) during the course of a patient's treatment has been shown to maximise survival.

The selection of the optimum treatment regimen for CRC remains difficult, with a number of effective choices available to patients and clinicians (Figure 2). The number of such alternatives is likely to increase over the coming years. Currently, the optimum first-line approach is to use either FOLFOX or FOLFIRI combined with a biological agent such as bevacizumab. The alternative regimen can thereafter be used as second-line treatment, again combined with a different biological agent, such as cetuximab. Although maybe not yet seen as an optimal marketing strategy by the pharmaceutical sector, as our knowledge of predictive tumour markers increases and as a more diverse range of targeted drugs becomes available, further dramatic progress in our ability to treat advanced CRC could lie in a more individualised and scientific process of treatment selection for the patient.

\section{REFERENCES}

Alberts SR, Horvath WL, Sternfeld WC, Goldberg RM, Mahoney MR, Dakhil SR, Levitt R, Rowland K, Nair S, Sargent DJ, Donohue JH (2005) Oxaliplatin, fluorouracil, and leucovorin for patients with unresectable liver-only metastases from colorectal cancer: a North Central Cancer Treatment Group phase II study. J Clin Oncol 23: 9243-9249

Andre T, Boni C, Mounedji-Boudiaf L, Navarro M, Tabernero J, Hickish T, Topham C, Zaninelli M, Clingan P, Bridgewater J, Tabah-Fisch I, de Gramont A (2004) Oxaliplatin, fluorouracil, and leucovorin as adjuvant treatment for colon cancer. $N$ Engl J Med 350: 2343-2351

Carlini LE, Meropol NJ, Bever J, Andria ML, Hill T, Gold P, Rogatko A, Wang H, Blanchard RL (2005) UGT1A7 and UGT1A9 polymorphisms predict response and toxicity in colorectal cancer patients treated with capecitabine/irinotecan. Clin Cancer Res 11: 1226-1236

Colorectal Meta-analysis Collaboration (2000) Palliative chemotherapy for advanced or metastatic colorectal cancer. Cochrane Database Syst Rev 2000: CD001545

Cunningham D, Humblet Y, Siena S, Khayat D, Bleiberg H, Santoro A, Bets D, Meuser M, Harstick A, Verslype C, Chau I, Van Cutsem E (2004) Cetuximab monotherapy and cetuximab plus irinotecan in irinotecan-refractory metastatic colorectal cancer. $N$ Engl J Med 351: $337-345$

Cunningham D, Pyrhonen S, James RD, Punt CJ, Hickish TF, Heikkila R, Johannesen TB, Starkhammar H, Topham CA, Awad L, Jacques C, Herait P (1998) Randomised trial of irinotecan plus supportive care versus supportive care alone after fluorouracil failure for patients with metastatic colorectal cancer. Lancet 352: 1413-1418

de Gramont A, Bosset JF, Milan C, Rougier P, Bouche O, Etienne PL, Morvan F, Louvet C, Guillot T, Francois E, Bedenne L (1997) Randomized trial comparing monthly low-dose leucovorin and fluorouracil bolus with bimonthly high-dose leucovorin and fluorouracil bolus plus continuous infusion for advanced colorectal cancer: a French intergroup study. J Clin Oncol 15: 808-815 de Gramont A, Figer A, Seymour M, Homerin M, Hmissi A, Cassidy J, Boni C, Cortes-Funes H, Cervantes A, Freyer G, Papamichael D, Le Bail N, Louvet C, Hendler D, de Braud F, Wilson C, Morvan F, Bonetti A (2000) Leucovorin and fluorouracil with or without oxaliplatin as first-line treatment in advanced colorectal cancer. J Clin Oncol 18: $2938-2947$

Diaz-Rubio E, Tabernero J, Van Cutsem E, Cervantes A, Andre T, Humblet Y, Soulie P, Corretge S, Kisker O, de Gramont A (2005) Cetuximab in combination with oxaliplatin/5-fluorouracil (5-FU)/folinic acid (FA) (FOLFOX-4) in the first-line treatment of patients with epidermal growth factor (EGFR)-expressing metastatic colorectal cancer: an international phase 11 study. J Clin Oncol 23(16S): (Abstract 3535, p 254s. Updated information presented at ASCO)

Douillard JY, Cunningham D, Roth AD, Navarro M, James RD, Karasek P, Jandik P, Iveson T, Carmichael J, Alakl M, Gruia G, Awad L, Rougier P (2000) Irinotecan combined with fluorouracil compared with fluorouracil alone as first-line treatment for metastatic colorectal cancer: a multicentre randomised trial. Lancet 355: $1041-1047$

Ellis LM, Curley SA, Grothey A (2005) Surgical resection after downsizing of colorectal liver metastasis in the era of bevacizumab. J Clin Oncol 23: $4853-4855$

Falcone A, Masi G, Murr R, Benedetti G, Bertetto O, Ferraldeschi R, Chiara S, Granetto C, Alabisio O, Ricci S (2006) Biweekly irinotecan, oxaliplatin, and infusional 5FU/LV (FOLFOXIRI) versus FOLFIRI as first-line treatment of metastatic colorectal cancer (MCRC): results of a randomized, phase III trial by the Gruppo Oncologico Nord Ovest (GONO). ASCO Gastrointest Cancer Symp Abstr 227

Folprecht G, Lutz MP, Schoffski P, Seufferlein T, Nolting A, Pollert P, Kohne CH (2006) Cetuximab and irinotecan/5-fluorouracil/folinic acid is a safe combination for the first-line treatment of patients with epidermal growth factor receptor expressing metastatic colorectal carcinoma. Ann Oncol 17: 450-456 
Gamelin E, Gamelin L, Bossi L, Quasthoff S (2002) Clinical aspects and molecular basis of oxaliplatin neurotoxicity: current management and development of preventive measures. Semin Oncol 29: $21-33$

Giacchetti S, Itzhaki M, Gruia G, Adam R, Zidani R, Kunstlinger F, Brienza S, Alafaci E, Bertheault-Cvitkovic F, Jasmin C, Reynes M, Bismuth $\mathrm{H}$, Misset JL, Levi F (1999) Long-term survival of patients with unresectable colorectal cancer liver metastases following infusional chemotherapy with 5-fluorouracil, leucovorin, oxaliplatin and surgery. Ann Oncol 10: $663-669$

Giacchetti S, Perpoint B, Zidani R, Le Bail N, Faggiuolo R, Focan C, Chollet P, Llory JF, Letourneau Y, Coudert B, Bertheaut-Cvitkovic F, LarregainFournier D, Le Rol A, Walter S, Adam R, Misset JL, Levi F (2000) Phase III multicenter randomized trial of oxaliplatin added to chronomodulated fluorouracil-leucovorin as first-line treatment of metastatic colorectal cancer. J Clin Oncol 18: $136-147$

Giantonio BJ, Catalano PJ, Meropol NJ, O'Dwyer PJ, Mitchell EP, Alberts SR, Schwartz MA, Benson AB (2005) High-dose bevacizumab improves survival when combined with FOLFOX4 in previously treated advanced colorectal cancer: results from the Eastern Cooperative Oncology Group (ECOG) study E3200. J Clin Oncol ASCO Annu Meet (Post Meet Proc) 23 (Abstract 2, p 1s)

Goldberg RM, Sargent DJ, Morant RS, Fuchs CS, Ramanathan RK, Williamson SK, Findlay BP, Pitot HC, Alberts SR (2004) A randomized controlled trial of fluorouracil plus leucovorin, irinotecan, and oxaliplatin combinations in patients with previously untreated metastatic colorectal cancer. J Clin Oncol 22: $23-30$

Grothey A (2003) Oxaliplatin-safety profile: neurotoxicity. Semin Oncol 30: $5-13$

Grothey A, Goldberg RM (2004) A review of oxaliplatin and its clinical use in colorectal cancer. Expert Opin Pharmacother 5: 2159-2170

Grothey A, Sargent D (2005) Overall survival of patients with advanced colorectal cancer correlates with availability of fluorouracil, irinotecan, and oxaliplatin regardless of whether doublet or single-agent therapy is used first line. J Clin Oncol 23: 9441 -9442

Grothey A, Sargent D, Goldberg RM, Schmoll HJ (2004) Survival of patients with advanced colorectal cancer improves with the availability of fluorouracil-leucovorin, irinotecan, and oxaliplatin in the course of treatment. J Clin Oncol 22: 1209-1214

Hicklin DJ, Ellis LM (2005) Role of the vascular endothelial growth factor pathway in tumor growth and angiogenesis. J Clin Oncol 23: $1011-1027$

Hochster H, Welles L, Hart L, Ramanathan RK, Hainsworth J, Jirau-Lucca G, Shpilsky A, Griffing S, Mass R, Emanuel D (2005) Safety and efficacy of bevacizumab (Bev) when added to oxaliplatin/fluoropyrimidine $(\mathrm{O} / \mathrm{F})$ regimens as first-line treatment of metastatic colorectal cancer (mCRC): TREE 1 \& 2. J Clin Oncol ASCO Annu Meet (Post Meet Proc) 23 (Abstract 3515, p 249s)

Hochster HS, Hart LL, Ramanathan RK, Hainsworth JD, Griffing S, Mass RD, Nagarwarla Y, Jirau-Lucca G, Shpilsky A, Childs BH (2006) TREE Study (TREE-2 cohort): TTP and TTF for three bevacizumab and oxaliplatin - fluorpyrimidine regimens. ASCO Gastrointest Cancer Symp Abstr 244

Hurwitz H, Fehrenbacher L, Novotny W, Cartwright T, Hainsworth J, Heim W, Berlin J, Baron A, Griffing S, Holmgren E, Ferrara N, Fyfe G, Rogers B, Ross R, Kabbinavar F (2004) Bevacizumab plus irinotecan, fluorouracil, and leucovorin for metastatic colorectal cancer. $N$ Engl J Med 350: $2335-2342$

Köhne CH, Folprecht G (2006) On prejudice and facts and choices. Ann Oncol 17: $185-187$

Köhne $\mathrm{CH}$, van Cutsem E, Wils J, Bokemeyer C, El-Serafi M, Lutz MP, Lorenz M, Reichardt P, Ruckle-Lanz H, Frickhofen N, Fuchs R, Mergenthaler HG, Langenbuch T, Vanhoefer U, Rougier P, Voigtmann R, Muller L, Genicot B, Anak O, Nordlinger B (2005) Phase III study of weekly high-dose infusional fluorouracil plus folinic acid with or without irinotecan in patients with metastatic colorectal cancer: European Organisation for Research and Treatment of Cancer Gastrointestinal Group Study 40986. J Clin Oncol 23: 4856-4865

Kozloff M, Cohn A, Christiansen N, Flynn P, Kabbinavar F, Robles R, Ulcickas-Yood M, Blanke C, Squier M, Grothey A (2006) Safety of bevacizumab (BV) among patients (pts) receiving first-line chemotherapy for metastatic colorectal cancer: updated results from a large observational study in the US (BRITE). ASCO Gastrointest Cancer Symp Abstr

Kubicka S, Arkenau H, Grothey A, Graeven U, Kretzschmar A, Greil R, Seufferlein T, Hinke A, Schmoll H, Porschen R (2006) Randomized trial of infusional 5-fluorouracil/folinic acid plus oxaliplatin (FUFOX) versus capecitabine plus oxaliplatin (CAPOX) as first line treatment of metastatic colorectal carcinoma (MCRC): final results of the safety and efficacy analysis. ASCO Gastrointest Cancer Symp Abstr

Leonard P, Seymour MT, James R, Hochhauser D, Ledermann JA (2002) Phase II study of irinotecan with bolus and high dose infusional 5-FU and folinic acid (modified de Gramont) for first or second line treatment of advanced or metastatic colorectal cancer. Br J Cancer 87: 1216-1220

Li S, Schmitz KR, Jeffrey PD, Wiltzius JJ, Kussie P, Ferguson KM (2005) Structural basis for inhibition of the epidermal growth factor receptor by cetuximab. Cancer Cell 7: $301-311$

Maughan TS, James RD, Kerr DJ, Ledermann JA, McArdle C, Seymour MT, Cohen D, Hopwood P, Johnston C, Stephens RJ (2002) Comparison of survival, palliation, and quality of life with three chemotherapy regimens in metastatic colorectal cancer: a multicentre randomised trial. Lancet 359: $1555-1563$

Meta-analysis Group in Cancer (1998a) Efficacy of intravenous continuous infusion of fluorouracil compared with bolus administration in advanced colorectal cancer. J Clin Oncol 16: $301-308$

Meta-Analysis Group In Cancer (1998b) Toxicity of fluorouracil in patients with advanced colorectal cancer: effect of administration schedule and prognostic factors. J Clin Oncol 16: 3537 - 3541

Nordlinger B, Sorbye H, Debois M, Praet M, Glimelius B, Poston GJ, Schlag PM, Walpole ET, Bechstein W, Gruenberger T (2005) Feasibility and risks of pre-operative chemotherapy (CT) with Folfox 4 and surgery for resectable colorectal cancer liver metastases (LM). Interim results of the EORTC Intergroup randomized phase III study 40983. J Clin Oncol ASCO Annu Meet (Post Meet Proc) 23 (Abstract 3528, p 253s)

Parkin DM, Bray F, Ferlay J, Pisani P (2005) Global cancer statistics, 2002. CA Cancer J Clin 55: 74-108

Polikoff J, Mitchell EP, Badarinath S, Graham CD, Jennis A, Chen TT, Gustafson T, Langer CJ (2005) Erbitux (Cetuximab) plus FOLFOX for colorectal cancer (EXPLORE): preliminary efficacy analysis of a randomized phase III trial. J Clin Oncol ASCO Annu Meet (Post Meet Proc) 23 (Abstract 3574, p 264s)

Punt CJ (2005) Irinotecan or oxaliplatin for first-line treatment of advanced colorectal cancer? Ann Oncol 16: $845-846$

Rhodes KE, Vallböhmer D, Zhang W, Yang DY, Yun J, Press O, Gordon M, Iqbal S, Lenz H (2005) Molecular predictor of Irinotecan (CPT-11) efficacy. J Clin Oncol ASCO Annu Meet Proc (Post-Meet Ed) 23 (Abstract 3560, p 261s)

Rich TA, Shepard RC, Mosley ST (2004) Four decades of continuing innovation with fluorouracil: current and future approaches to fluorouracil chemoradiation therapy. J Clin Oncol 22: 2214-2232

Rougier P, Raoul J, Van Laethem J-L, Peeters M, Husseini F, Brezault C, Cals L (2004) Cetuximab+FOLFIRI as first-line treatment for metastatic colorectal CA. Proc Am Soc Clin Oncol 23, (Abstract 3513, p 248)

Rougier P, Van Cutsem E, Bajetta E, Niederle N, Possinger K, Labianca R, Navarro M, Morant R, Bleiberg H, Wils J, Awad L, Herait P, Jacques C (1998) Randomised trial of irinotecan $v s$ fluorouracil by continuous infusion after fluorouracil failure in patients with metastatic colorectal cancer. Lancet 352: $1407-1412$

Russo A, Corsale S, Cammareri P, Agnese V, Cascio S, Di Fede G, Macaluso M, Bazan V (2005) Pharmacogenomics in colorectal carcinomas: future perspectives in personalized therapy. J Cell Physiol 204: $742-749$

Saltz LB, Cox JV, Blanke C, Rosen LS, Fehrenbacher L, Moore MJ, Maroun JA, Ackland SP, Locker PK, Pirotta N, Elfring GL, Miller LL (2000) Irinotecan plus fluorouracil and leucovorin for metastatic colorectal cancer. Irinotecan Study Group. N Engl J Med 343: 905-914

Sargent DJ, Niedzwiecki D, O'Connell MJ, Schilsky RL (2001) Recommendation for caution with irinotecan, fluorouracil, and leucovorin for colorectal cancer. $N$ Engl J Med 345: 144-145

Scappaticci FA, Fehrenbacher L, Cartwright T, Hainsworth JD, Heim W, Berlin J, Kabbinavar F, Novotny W, Sarkar S, Hurwitz H (2005) Surgical wound healing complications in metastatic colorectal cancer patients treated with bevacizumab. J Surg Oncol 91: 173-180

Segaert S, Tabernero J, Chosidow O, Dirschka T, Elsner J, Mancini L, Maughan T, Morere JF, Santoro A, Sobrero A, Van Cutsem E, Layton A (2005) The management of skin reactions in cancer patients receiving epidermal growth factor receptor targeted therapies. J Dtsch Dermatol Ges 3: $599-606$

Seymour MT (2005) Fluorouracil, oxaliplatin and CPT-11 (irinotecan), use and sequencing (MRC FOCUS): a 2135-patient randomized trial in advanced colorectal cancer (ACRC). J Clin Oncol ASCO Annu Meet Proc (Post-Meet Ed) 23 (Abstract 3518, p 250s) 
Simmonds PC (2000) Palliative chemotherapy for advanced colorectal cancer: systematic review and meta-analysis. Colorectal Cancer Collaborative Group. BMJ 321: $531-535$

Thirion P, Michiels S, Pignon JP, Buyse M, Braud AC, Carlson RW, O'Connell M, Sargent P, Piedbois P (2004) Modulation of fluorouracil by leucovorin in patients with advanced colorectal cancer: an updated metaanalysis. J Clin Oncol 22: 3766-3775

Tournigand C, Andre T, Achille E, Lledo G, Flesh M, Mery-Mignard D, Quinaux E, Couteau C, Buyse M, Ganem G, Landi B, Colin P, Louvet C, de Gramont A (2004) FOLFIRI followed by FOLFOX6 or the reverse sequence in advanced colorectal cancer: a randomised GERCOR study. J Clin Oncol 22: 229-237

Twelves C, Gollins S, Grieve R, Samuel L (2006) A randomised cross-over trial comparing patient preference for oral capecitabine and 5fluorouracil/leucovorin regimens in patients with advanced colorectal cancer. Ann Oncol 17: 239-245

Twelves C, Wong A, Nowacki MP, Abt M, Burris III H, Carrato A, Cassidy J, Cervantes A, Fagerberg J, Georgoulias V, Husseini F, Jodrell D, Koralewski P, Kroning H, Maroun J, Marschner N, McKendrick J, Pawlicki M, Rosso R, Schuller J, Seitz JF, Stabuc B, Tujakowski J, Van
Hazel G, Zaluski J, Scheithauer W (2005) Capecitabine as adjuvant treatment for stage III colon cancer. N Engl J Med 352: 2696-2704

Van Cutsem E, Hoff PM, Harper P, Bukowski RM, Cunningham D, Dufour P, Graeven U, Lokich J, Madajewicz S, Maroun JA, Marshall JL, Mitchell EP, Perez-Manga G, Rougier P, Schmiegel W, Schoelmerich J, Sobrero A, Schilsky RL (2004a) Oral capecitabine $v s$ intravenous 5-fluorouracil and leucovorin: integrated efficacy data and novel analyses from two large, randomised, phase III trials. Br J Cancer 90: $1190-1197$

Van Cutsem E, Mayer RJ, Gold P, Stella PJ, Cohen A, Pippas AW, Windt P, Molloy P, Lenz H-J (2004b) Correlation of acne rash and tumor response with cetuximab monotherapy in patients with colorectal cancer refractory to both irinotecan and oxaliplatin. EORTC-NCI-AACR Symp (Abstract 279)

Van Cutsem E, Labianca R, Hossfeld D, Bodoky G, Roth A, Aranda E, Nordlinger B, Assadourian S, Wang K, Cunningham III DP (2005) Randomized phase III trial comparing infused irinotecan/5-fluorouracil (5-FU)/folinic acid (IF) versus 5-FU/FA (F) in stage III colon cancer patients (pts). (PETACC 3). J Clin Oncol ASCO Annu Meet Proc (PostMeet Ed) 23 (Abstract LBA8) 